\title{
Evaluation of the Vulnerability to Groundwater Pollution of the Makiso Municipality in Kisangani (DR Congo) Using the DRASTIC Parametric Method and GIS
}

\section{Pierre Mashala $^{1}$, Portance Kasongo ${ }^{1}$, Albert Komba ${ }^{2}$, Faidance Mashauri ${ }^{3}$, Guers Maloba ${ }^{4}$, Robert Wazi ${ }^{5}$}

\author{
${ }^{1}$ Department of Geology, Faculty of Sciences, University of Lubumbashi, Lubumbashi, DR Congo \\ ${ }^{2}$ Department of Geology, Faculty of Sciences, University of Likasi, Likasi, DR Congo \\ ${ }^{3}$ Faculty of Geological Sciences, University of Uélé, Isiro, DR Congo \\ ${ }^{4}$ Department of Geology, Faculty of Sciences, University of Kisangani, Kisangani, DR Congo \\ ${ }^{5}$ Department of Geology, Faculty of Applied Sciences, Official University of Bukavu, DR Congo \\ Email: kasmutombo@gmail.com
}

\begin{abstract}
How to cite this paper: Mashala, P., Kasongo, P., Komba, A., Mashauri, F., Maloba, G. and Wazi, R. (2022) Evaluation of the Vulnerability to Groundwater Pollution of the Makiso Municipality in Kisangani (DR Congo) Using the DRASTIC Parametric Method and GIS. Journal of Water Resource and Protection, 14, 126-141. https://doi.org/10.4236/jwarp.2022.142008
\end{abstract}

Received: December 22, 2021

Accepted: February 20, 2022

Published: February 23, 2022

Copyright $\odot 2022$ by author(s) and Scientific Research Publishing Inc. This work is licensed under the Creative Commons Attribution International License (CC BY 4.0).

http://creativecommons.org/licenses/by/4.0/

\section{(c) (i) Open Access}

\begin{abstract}
The Makiso municipality is located in an urban area influenced by a very high rate of land occupation by houses. This land use has an impact on the quality of the groundwater exploited by wells and springs. This groundwater helps to make up for the deficit caused by the lack of a water distribution network. It is also threatened by pollution from human activities. In order to protect the groundwater in Makiso municipality from pollution, the study of the intrinsic vulnerability assessment in the aquifers was carried out by applying the DRASTIC method and the Geographic Information System (GIS). The results obtained using this method were grouped into two degrees of vulnerability (medium and high), with variations in DRASTIC indices of [141 - 145] for the medium degree and [146 - 175] for the high degree. The high vulnerability class is the most dominant, with a percentage of $96.5 \%$ of the study area. The medium vulnerability class, which represents $3.5 \%$ of the area of the Makiso municipality, is mainly located in the western (medical plateau district), central (Lualaba district) and southern (commercial district) sectors in the form of isolated pockets. A comparison of the nitrate distribution map with the final vulnerability map shows that the areas defined as highly vulnerable by the DRASTIC method and the areas with high nitrate concentrations (above $0.11 \mathrm{mg} / \mathrm{l}$ ) are in agreement. On the other hand, there are other areas with low nitrate concentrations (below $0.05 \mathrm{mg} / \mathrm{l}$ ) which correspond to the high vulnerability indices.
\end{abstract}




\section{Keywords}

Vulnerability, Pollution, Validation, DRASTIC, GIS, Makiso, Kisangani, DR Congo

\section{Introduction}

The vulnerability of a groundwater body to pollution is a measure of how easily it can be affected by pollution [1] [2]. This pollution can be generated by a point source (landfill, cemetery, domestic or industrial wastewater discharge, etc.), linear (wastewater network, agricultural drainage network, etc.) or diffuse (chemical fertilizers, pesticides, herbicides, domestic wastewater application, etc.) [3]. In urban or industrial environments, groundwater can quickly become fragile to overexploitation or contamination. Some researchers have developed tools for the protection and preservation of groundwater.

Mapping vulnerability to pollution makes it possible to identify areas at high risk of contamination, regardless of the type of pollutant. It should in principle condition urban land use plans or at least allow the targeting of areas where strict protection measures should be adopted and this is within the framework of predicting the spread of pollutants from developments.

The groundwater of the Makiso municipality is subject to multiform pollution that weakens this vast area of the city of Kisangani. It is mainly fed by rainwater, but also by the infiltration of water from the rivers (Congo River, Tshopo River and their tributaries) that cross the municipality and are in permanent communication with the alluvial aquifer. The groundwater resources of this aquifer are increasingly solicited to cover the ever-growing water needs in various fields (food, irrigation, industry, etc.). However, these groundwater resources are threatened by several factors linked in general to the poor environmental management. Discharges of domestic or industrial water into the groundwater without prior treatment and without any measures to protect the water resource can pollute the groundwater. In this urban area, latrines are located upstream, at a distance of less than $15 \mathrm{~m}$ from traditional water sources and wells.

Thus, this work was carried out with the aim of assessing the vulnerability to groundwater pollution of the Makiso municipality in Kisangani using the DRASTIC method and GIS. The DRASTIC method is presented in the form of numerical rating systems, based on the consideration of different factors influencing the hydrogeological system [4]. The application of this methodology cannot be possible without the use of Geographic Information Systems (GIS), due to the very large amount of data required necessary [2].

\section{Methodology}

\subsection{General Presentation of the Study Area}

Makiso is one of the six municipalities of the city of Kisangani, covering an area 
of about $27 \mathrm{~km}^{2}$. It is located in the centre of the city (Figure 1), between latitude $0.5^{\circ}$ and $0.57^{\circ} \mathrm{N}$ and between longitude $25.12^{\circ}$ and $25.22^{\circ} \mathrm{E}$. The climate is of the hot and humid equatorial type, belonging to group Af of the Köppen classification. The average temperature of the coldest month is $18^{\circ} \mathrm{C}$. The average rainfall in the driest month is more than $60 \mathrm{~mm}$ and the temperature range is less than $5^{\circ} \mathrm{C}[5]$.

Rainfall is abundant despite a decrease from December to February and from June to August, resulting in two short, relatively dry seasons [6] [7]. The municipality is drained mainly by the Congo River in the south and the Tshopo River in the north. These two major rivers in turn collect water from numerous tributaries, most of which flow through the municipality.

Geologically, the Makiso municipality is characterised by Upper Precambrian (Lindian), Mesozoic (Lueki and Kisanani Groups) and Cenozoic (Central Cuvette Supergroup) formations. The lithological descriptions presented in this work are those proposed by [8] [9] and [10] [11], recently updated by [12].

- The Lindian is mainly composed of sandstone and shale, with intercalations of limestone and dolomite. The whole is little or no metamorphic (chlorite stage). The existence of unconformities allows it to be subdivided into three groups: Aruwimi, Lokoma and Ituri. The lower group, the Ituri, is composed of arkose and quartzites on which limestones and dolomites lie. It ends with shales containing intercalations of limestones and dolomites. The intermediate group or Lokoma starts with arkoses and conglomerates, on which lie shales

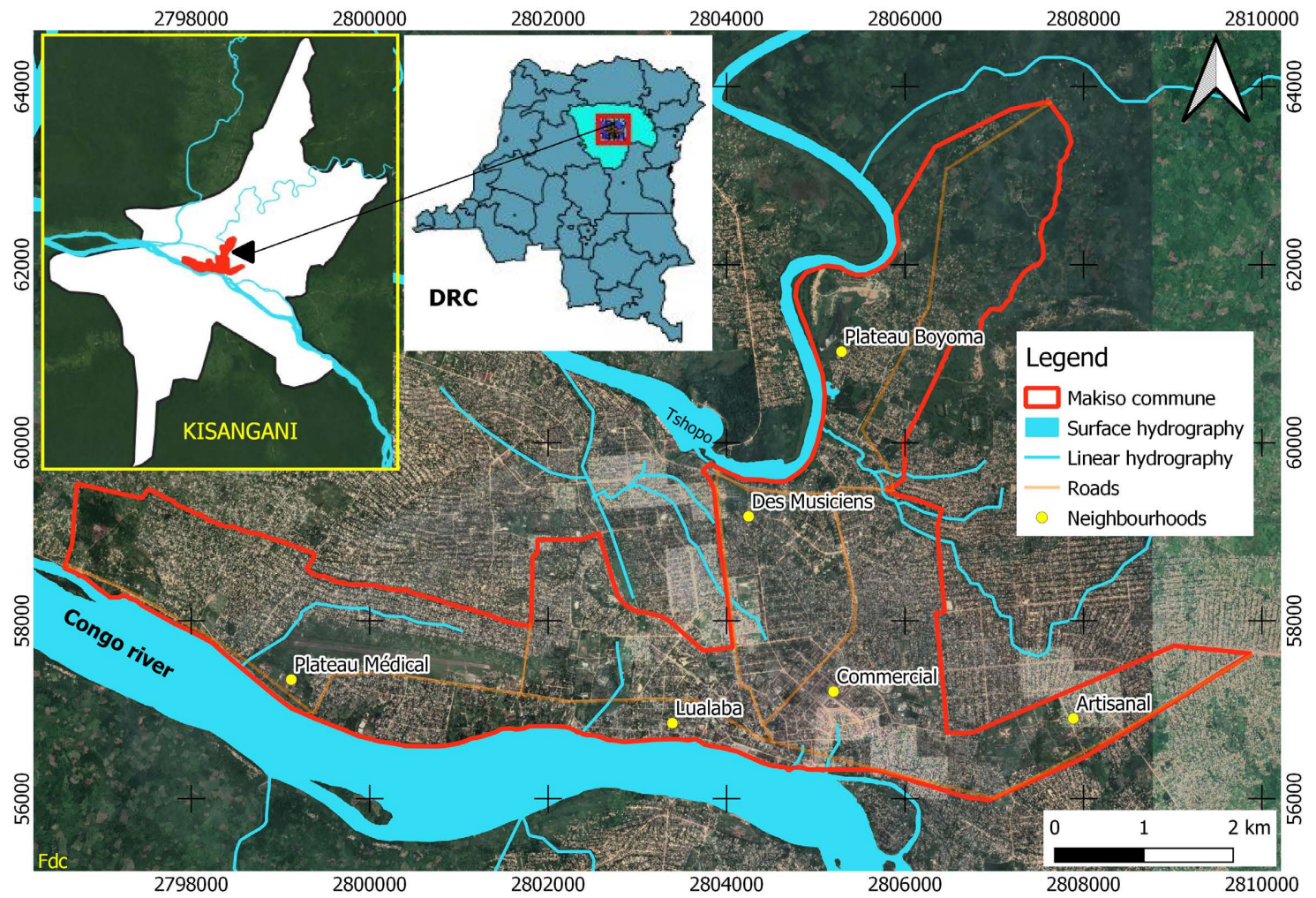

Figure 1. Location map of the study area. 
containing intercalations of limestone and dolomites. The upper group or Aruwimi has quartzites and arkoses at the base, locally conglomeratic, on which shales lie. The Aruwimi ends with a thick formation of fine, red arkose.

- The cover lands comprise Mesozoic and Cenozoic formations. The Mesozoic is only found in the valley of the Congo River and its tributaries. It is represented by the Lueki Group of Triassic age (typical red facies rock) and the Kisangani Group of Upper Jurassic age. These formations are subhorizontal and are mainly composed of soft sandstones and mudstones with calcareous marl and sandstone and bituminous shales. The Cenozoic covers the oldest formations. It is composed of more or less clayey sands, sandy gravels with some conglomerates at the base and lateritic layers.

\subsection{Collection and Integration of Hydrogeological Data in the GIS}

The data collection equipment consists of a sonic piezometer probe (Heron Dipper-T Water-Level Meters) to measure the water level in the wells, a Garmin GPS (Etrex 30), calibrated to the geographical coordinates of the Kisangani geodetic point, a plumb bob and a tape measure used to measure the depth and diameter of the wells respectively, a field notebook and a digital camera.

A total of eighty-one (81) measurement points were selected to achieve the most uniform geographical coverage possible across the study area.

The cartographic integration of well data was carried out with QGIS software using digital data files from the hydrogeological database established from the field data including the various digitized maps (geological, topographical, hydrographic...).

The interpolation of some hydrogeological data by geostatistical processing was done using Surfer software. The most appropriate interpolation method to perform the analysis was the Kriging method.

\subsection{Vulnerability Assessment Method Used}

There is no absolute method for assessing the vulnerability of groundwater [13]. In the literature, several methods for assessing vulnerability to pollution have been adopted. They range from the most complex with models taking into account physical, chemical and biological processes in the saturated zone, to weighting methods between different criteria affecting this vulnerability. These include the following methods: DRASTIC [14], GOD [15], AVI [16], SINTACS [17] [18].

In the present study, we used the DRASTIC method because of the concordance of the parameters to be measured found in our study area. This method involves parameters relating to the recharge of the water table, the nature of the soil, the topographical slope and the hydrogeological characteristics, in particular, the porosity and hydraulic conductivity of the medium under consideration. This method is based on the fact that the contaminant spreads in the environ- 
ment from the soil surface by infiltration of precipitation and the type of contaminant does not influence the degree of vulnerability. It is based on the evaluation of seven parameters: depth of the water table (D), recharge (R), type of aquifer (A), type of soil (S), topography (T), impact of the vadose zone (I) and hydraulic conductivity $(\mathrm{C})$.

Each of these parameters is assigned a weight (predetermined value) between 1 and 5, which reflects the importance of the parameter in the contaminant transport and attenuation processes. A dominant parameter is assigned a weight of 5 , while a parameter with less impact on the fate of a contaminant is assigned a weight of 1 . The DRASTIC parameter weights used are those defined by [14].

These seven parameters are associated with scores ranging from 1 to 10 , defined in terms of ranges of values (classes). The lowest score represents the conditions of lowest vulnerability to contamination. Once the different classes have been defined and their scores assigned, the method determines the DRASTIC index (Id) which characterizes the degree of vulnerability of a given sector of the water table. The higher the index (Id) calculated, the greater the vulnerability. The DRASTIC vulnerability index is calculated by summing the products of the scores (ratings) by the weights of the corresponding parameters according to the following formula:

$$
\begin{aligned}
\mathrm{Id}= & (\mathrm{Dr} \times \mathrm{Dw})+(\mathrm{Rr} \times \mathrm{Rw})+(\mathrm{Ar} \times \mathrm{Aw})+(\mathrm{Sr} \times \mathrm{Sw}) \\
& +(\operatorname{Tr} \times \mathrm{Tw})+(\mathrm{Ir} \times \mathrm{Iw})+(\mathrm{Cr} \times \mathrm{Cw})
\end{aligned}
$$

where, $\mathrm{D}, \mathrm{R}, \mathrm{A}, \mathrm{S}, \mathrm{T}, \mathrm{I}, \mathrm{C}$, are the parameters listed above; $\mathrm{r}$ : the rating given to each parameter and w: the weighting factor given to each parameter.

The index calculated in this way represents a measure of the level of risk of contamination of the hydrogeological unit to which it relates. This risk increases with the value of the index. Formula (2) is used to convert DRASTIC indices into percentages.

$$
\text { Id in } \%=(I d-23 / 203) \times 100
$$

Id is the calculated vulnerability index of the hydrogeological unit. This percentage can have a maximum value of 100 (226) and a minimum value of 0 (23) (Table 1).

In this study, the assessment of vulnerability to pollution was carried out using the DRASTIC method and QGIS software. The latter allowed the integration and he latter allowed the integration and spatial distribution of the weighted scores attributed for this method and their representation in shape file format. This technique was used by [19]. In summary, the methodology used in this work is shown in the flowchart in Figure 2.

\section{Results and Interpretations}

\subsection{Thematic Maps of DRASTIC Parameters}

\subsubsection{Depth of Groundwater (D)}

The depth gives an idea of how far the pollutant has to travel before reaching the 
Table 1. DRASTIC index and degree of vulnerability [3].

\begin{tabular}{rc}
\hline DRASTIC Index (Id) & Degree of vulnerability \\
\hline 23 to $84(0 \%$ to $30 \%)$ & Very low \\
85 to $114(31 \%$ to $45 \%)$ & Low \\
115 to $145(46 \%$ to $60 \%)$ & Medium \\
146 to $175(61 \%$ to $75 \%)$ & High \\
176 to $226(76 \%$ to $100 \%)$ & Very high \\
\hline
\end{tabular}

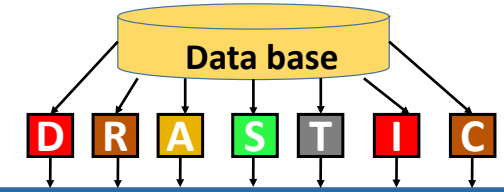

Calculation of vulnerability values using the DRASTIC method

\section{Integration of data in the GIS}

1

Index Map

Index classifications

DRASTIC pollution

vulnerability map
Conversion of DRASTIC

indices into \% vulnerability

Classification of \% by

hydrogeological vulnerability

Figure 2. General outline of the methodology.

water table [3]. The evaluation of this parameter was based on the water level values taken directly in the wells studied using a hand-held probe with a light and sound indicator. A total of eighty-one (81) measurement points were chosen to obtain the most uniform geographical coverage possible. The values obtained were classified according to the DRASTIC rating system. The depth map was established by interpolating the values by geostatistical analysis (Kriging method) under the Surfer software.

Three classes are distinguished on the map, ranging from $0.02 \mathrm{~m}$ depth to more than $7.82 \mathrm{~m}$, but most of Makiso municipality is located at a depth of more than $1.5 \mathrm{~m}$ (eastern and western parts of the municipality). The following classes are summarised in Table 2.

\subsubsection{Net groundwater Recharge ( $R$ )}

The effective or net recharge defines the quantity of water, per unit area, that infiltrates and reaches the saturated zone. This water is a factor in the transfer of pollutants to the groundwater through the vadose zone. The estimation of recharge is difficult to determine because it is discontinuous. In order to estimate recharge, we used test wells where we assumed that no sampling had taken place. We proceeded by taking the difference between the static levels recorded at these wells during the rainy $(n 2)$ and dry $(n 1)$ periods and the highest recharge value (a). A coefficient $(p)$ was therefore determined and multiplied by the infiltration calculated from rainfall data averaging $193 \mathrm{~mm} /$ year from regions with the same 
Table 2. Classes, ratings, indices and weights of parameter D (depth of groundwater).

\begin{tabular}{cccc}
\hline Class D (m) & Rating $(\mathrm{r})$ & Index & Weight \\
\hline $0.0-1.5$ & 10 & 50 & \\
$1.5-4.5$ & 9 & 45 & 5 \\
$4.5-9.0$ & 7 & 35 & \\
\hline
\end{tabular}

climate or geological characteristics as ours. This method has already been adopted by the authors [2].

$$
p=\frac{n 2-n 1}{a} \text { and } \mathrm{Rn}=p \times \mathrm{R}
$$

with $\mathrm{Rn}$ : the calculated net recharge and $\mathrm{R}$ the recharge determined over the whole study area and which is homogeneous.

The definition of the recharge classes (R) was based on the notation given by [20]. According to the DRASTIC notation, the spatial variation of recharge has only one class (Table 3 ).

\subsubsection{Aquifer Environment (A)}

The aquifer environment parameter refers to the lithology of the aquifer and plays a role in the trapping of pollutants, including nitrates, which escape the absorption capacity of the soil. Its identification was based on the lithological logs of the wells in the study area. The analysis of these data illustrated that the aquifer material in the Makiso municipality is essentially made up of gravel with sand on the one hand and very fine sand on the other. The indices corresponding to this parameter were estimated according to the notation illustrated in $\mathrm{Ta}$ ble 4 .

\subsubsection{Soil Types (S)}

The type of soil has an impact on the fringe of water that infiltrates through the soil to reach the groundwater resources and thus the vertical migration of pollutants through the unsaturated zone. It thus influences the migration time of contaminants to the groundwater. The information gathered from the field observations was used to define the nature of the soil in the Makiso municipality. The index values were determined according to the classes reported in (Table 5).

\subsubsection{Topography or Slope (T)}

The topography parameter is represented in the DRASTIC method by the slope values in (\%), this parameter translates the aptitude for runoff and infiltration of surface water towards the groundwater and therefore reflects the capacity of this water to introduce polluting agents towards the groundwater. The greater the slope of the land, the greater the runoff of water and consequently the lower the contamination of groundwater. On the other hand, an area with a low slope has a tendency to retain water for a long period of time, which allows a greater potential for contaminant migration. 
Table 3. Class, rating, index and weight of the parameter $\mathrm{R}$ (effective groundwater recharge).

\begin{tabular}{cccc}
\hline Class R (mm/year) & Rating $(\mathrm{r})$ & Index & Weight \\
\hline $0.0-5.0$ & 1 & 4 & 4
\end{tabular}

Table 4. Classes, weights, scores and indices for parameter A (aquifer environment).

\begin{tabular}{cccc}
\hline Class A & Rating $(\mathbf{r})$ & Index & Weight \\
\hline Gravel with sand & 8 & 24 & 3 \\
Very fine sand & 7 & 21 & \\
\hline
\end{tabular}

Table 5. Classes, weights, scores and indices of parameter S (soil type).

\begin{tabular}{cccc}
\hline Class S & Rating (r) & Index & Weight \\
\hline Absent & 10 & 20 & \\
Sand & 9 & 18 & 2 \\
Clay & 1 & 2 & \\
\hline
\end{tabular}

The different slope values were determined on the basis of SRTM images using QGIS. The definition of the slope classes (T) was based on the notation given by [9]. The classes thus retained for the slope parameter " $\mathrm{T}$ " are summarized in Table 6.

\subsubsection{Impact of the Vadose Zone (I)}

The vadose zone is an unsaturated zone between the soil layer and the water table. The nature of this zone is an important parameter in the vulnerability assessment, as it influences the speed of propagation of pollutants into the aquifer. The influence of this zone in the potential pollution of the aquifer depends mainly on its permeability and attenuation capacity. The process of calculating and mapping Theme "I" is the same as for the saturated zone (Aquifer Environment A). In this study, the nature of the vadose zone was determined by interpolation and correlation of observation well data (lithostratigraphic logs). Interpolation of the relative ratings of this parameter allowed two classes of zones to be distinguished, with different degrees of vulnerability (Table 7).

\subsubsection{Hydraulic Conductivity of the Aquifer (C)}

The hydraulic conductivity controls the speed of propagation of pollutants in the aquifer. It depends on the lithology of the aquifer. The higher this parameter is, the faster the transfer of pollutants. This parameter could not be evaluated from the interpretation of pumping tests. These tests were few in number or poorly carried out and proved to be unreliable. However, in order to be able to extrapolate to the entire study area, we used the table for estimating permeability based on the lithological nature of the aquifers [1].

The average values thus determined for the Makiso municipality make it possible to use the DRASTIC rating tables to highlight the different zones, each 
Table 6. Classes, weights, scores and indices of parameter $\mathrm{T}$ (land slopes).

\begin{tabular}{cccc}
\hline Class T (\%) & Rating $(\mathbf{r})$ & Index & Weight \\
\hline $0.0-2.0$ & 10 & 10 & 1 \\
$2.0-6.0$ & 9 & 9 & \\
\hline
\end{tabular}

Table 7. Classes, weights, score and index of parameter I (impact of the vadose zone).

\begin{tabular}{cccc}
\hline Class I & Rating $(\mathbf{r})$ & Index & Weight \\
\hline Clay-Sand & 7 & 35 & 5 \\
Sandy Clay & 2 & 10 &
\end{tabular}

characterized by a partial index $\mathrm{C}$. The variation in the hydraulic conductivity of the water table makes it possible to distinguish two classes presented in Table 8.

The different parameters described above have enabled us to draw up thematic maps. On each of these maps (Figure 2), the areas characterized by a partial vulnerability index of the corresponding parameter are delineated.

\subsection{Mapping of Groundwater Vulnerability in the Makiso Municipality}

The combination of the different parameters assessed has resulted in the DRASTIC index map (Figure 3). The risk of groundwater contamination increases with the value of the index. It can have a maximum value of $226(100 \%)$ and a minimum value of $23(0 \%)$. The different indices were classified according to the ranges adopted by [19], taking into account the characteristics of the study area. The calculation of the percentages of vulnerability using the formula for converting DRASTIC indices into percentages [ID (\%) $=($ ID -23$) \times 100 / 203$ ] and from the DRASTIC indices obtained, it was possible to obtain a classification into two areas of vulnerability: 1) medium vulnerability and 2) high vulnerability. These two classes are shown in Table 9 and Figure 4.

This classification of the percentages of DRASTIC indices has made it possible to obtain the intrinsic vulnerability map of the Makiso municipality to groundwater pollution. The DRASTIC indices obtained at the municipality level vary from 141 (58\%) to 175 (75\%). The analysis of the map below shows dominance of high vulnerability areas in the majority of the Makiso aquifer.

On this map, two degrees of vulnerability are highlighted. These are the:

1) Medium degree of vulnerability: this represents only $3.5 \%$ of the mapped areas. This class reflects a medium vulnerability to pollution. The medium vulnerability in this area can be explained by the fact that the depth is greater than or equal to $1.5 \mathrm{~m}$.

2) Thus, allowing the contaminant to take a long time to reach the water table and the nature of the aquifer, as well as the vadose zone characterized by a fine texture. Indeed, materials with a fine texture promote certain processes such as adsorption, the more the vadose zone is rich in fine particles, the greater the adsorption of pollutants, and the greater the protection of the groundwater. In 


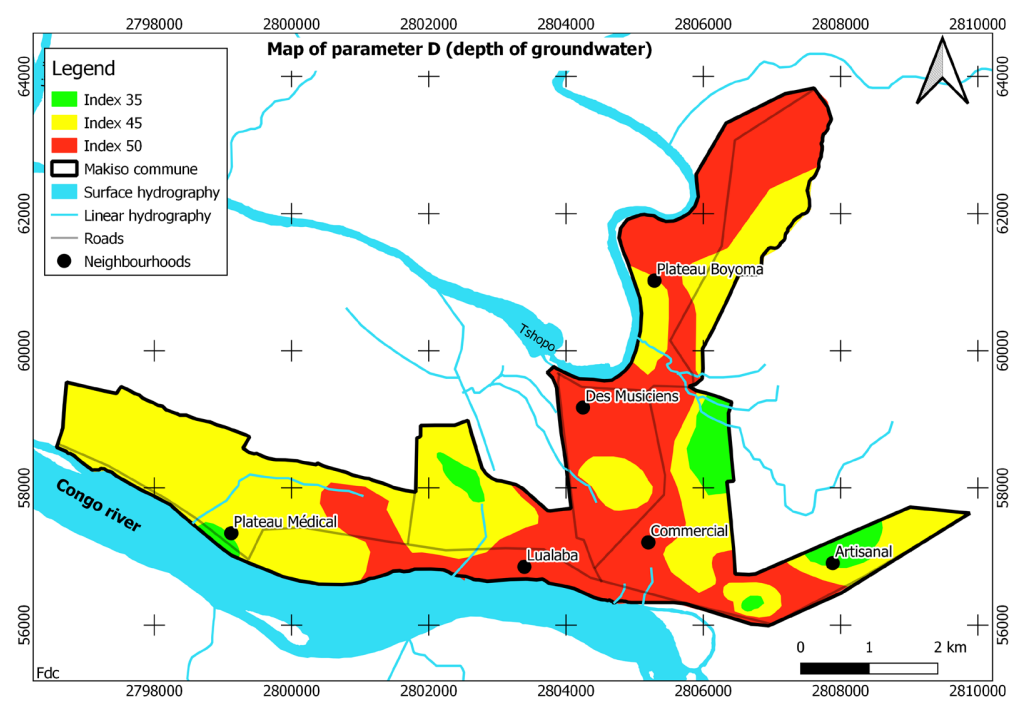

(a)

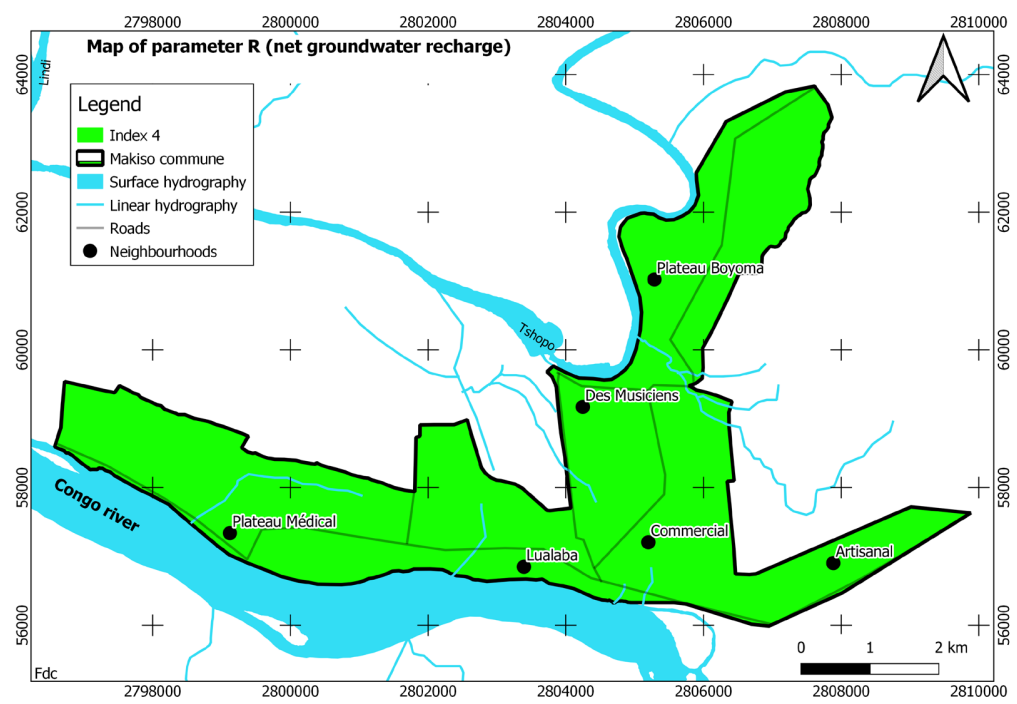

(b)

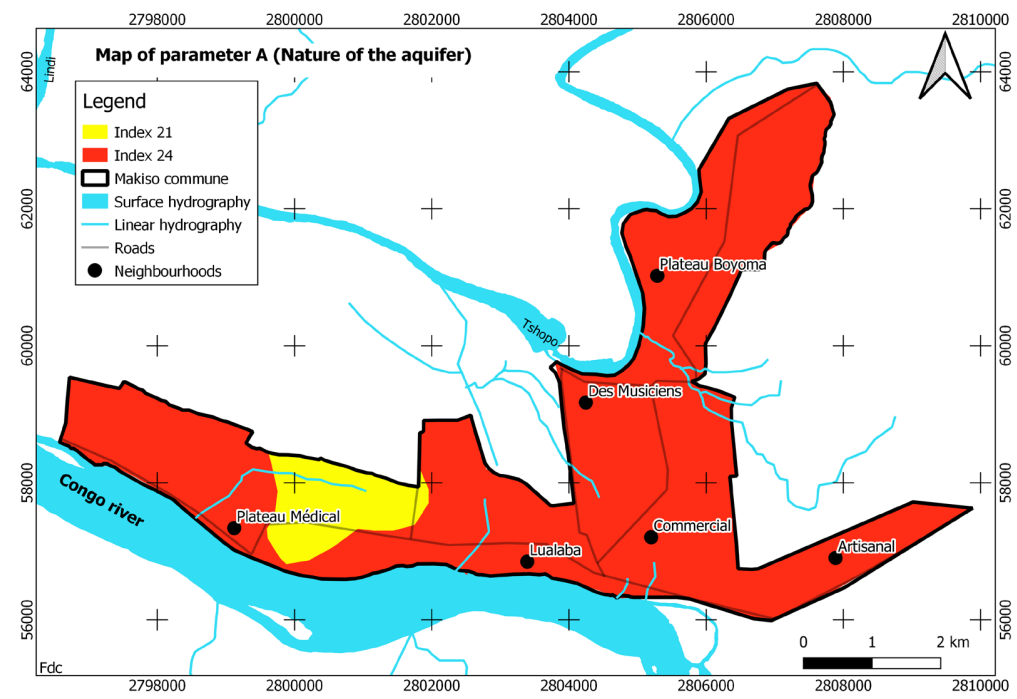

(c) 


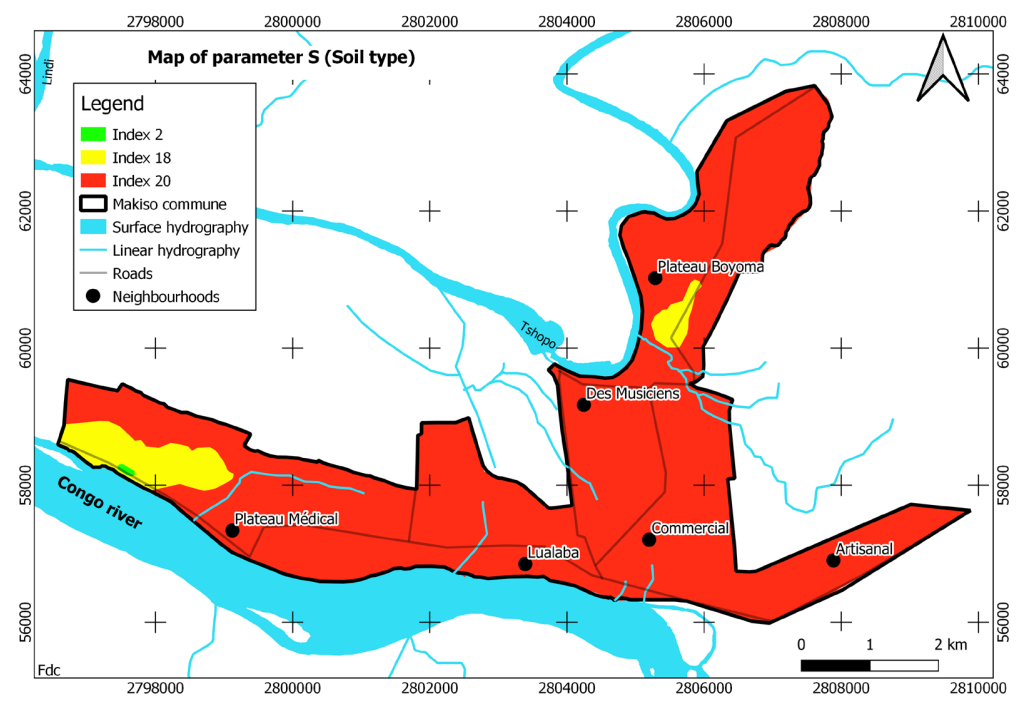

(d)

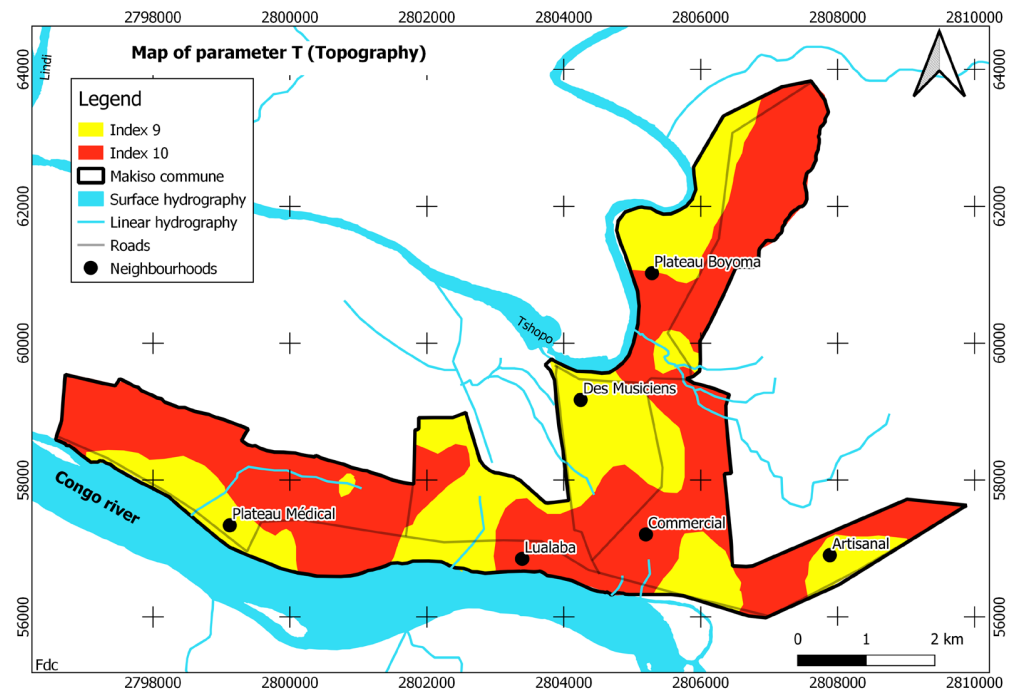

(e)

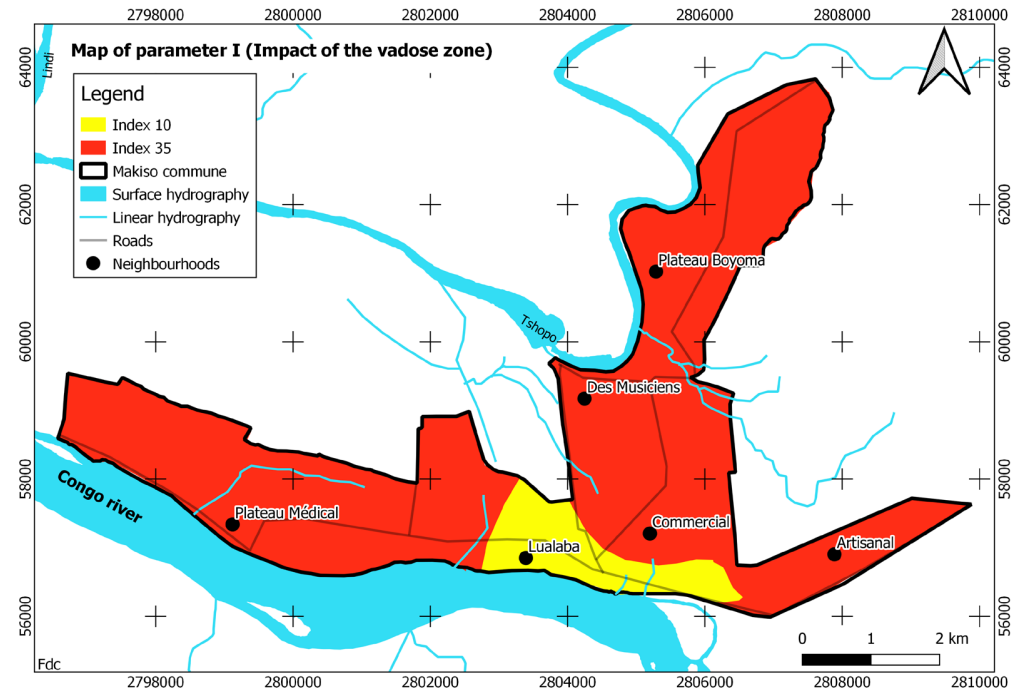

(f) 


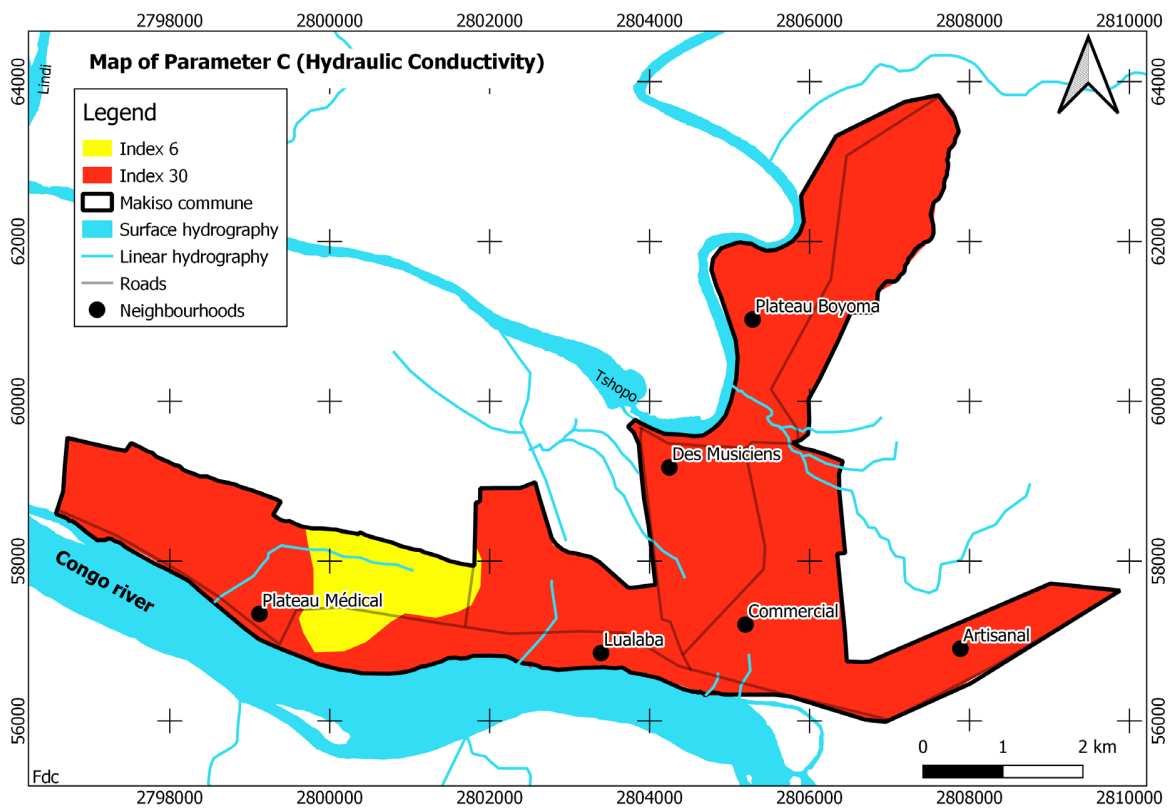

(g)

Figure 3. Presentation of the thematic maps. D-parameter (a); R-parameter (b); A-parameter (c); S-parameter (d); T-parameter (e); I-parameter (f); C-parameter (g).

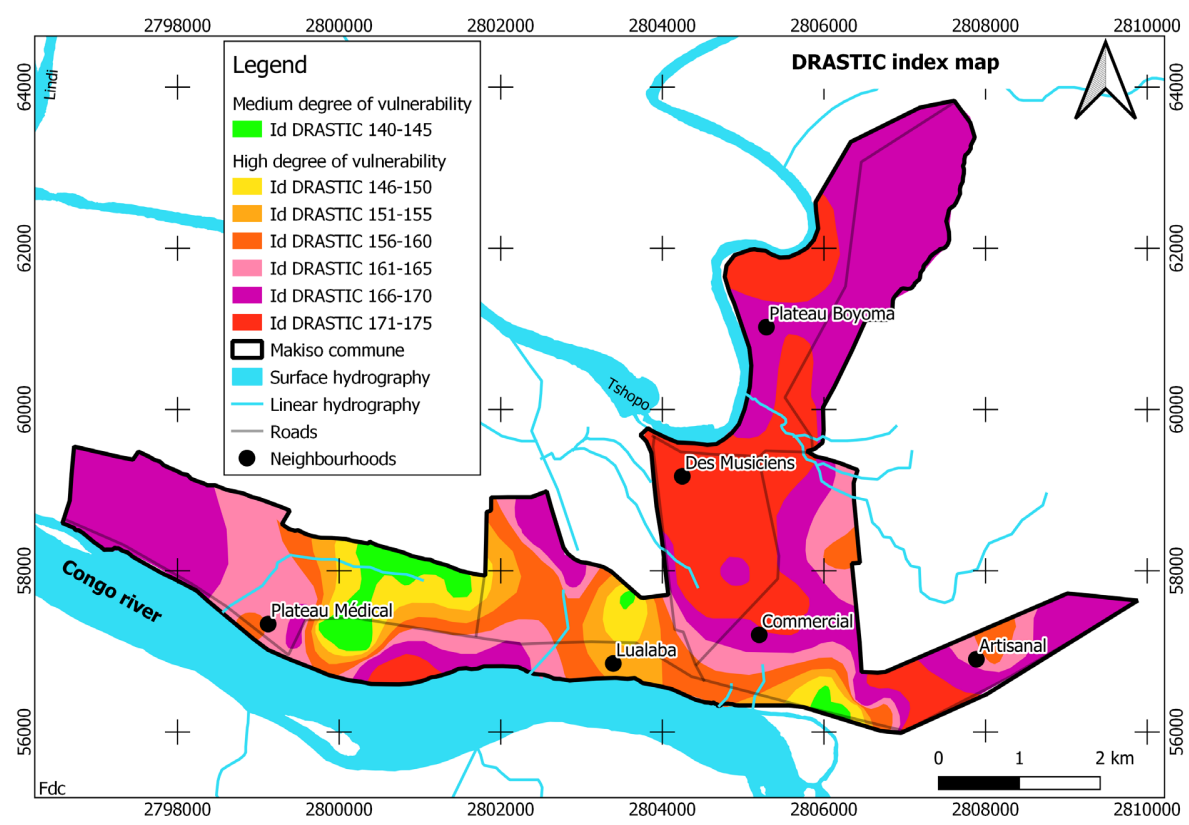

Figure 4. Groundwater pollution vulnerability map of Makiso municipality according to the DRASTIC method.

Table 8. Classes, weights, scores and indices of parameter $\mathrm{C}$ (aquifer hydraulic conductivity).

\begin{tabular}{cccc}
\hline Class C (m/s) & Rating $(\mathrm{r})$ & Index & Weight \\
\hline$>9.4 \times 10^{-4}$ & 10 & 30 & 3 \\
$4.70 \times 10^{-5}-1.47 \times 10^{-4}$ & 2 & 6 &
\end{tabular}


Table 9. Vulnerability classification of groundwater in Makiso municipality.

\begin{tabular}{cccc}
\hline $\begin{array}{c}\text { DRASTIC Index Value } \\
\text { (DI) }\end{array}$ & $\begin{array}{c}\text { Degree of } \\
\text { vulnerability }\end{array}$ & $\begin{array}{c}\text { DRASTIC Index (DI) } \\
\text { to \% }\end{array}$ & \%Area \\
\hline 141 to 145 & Medium & 58 to 60 & 3.5 \\
146 to 175 & High & 61 to 75 & 96.5 \\
\hline
\end{tabular}

these areas, the vadose zone containing sandy clays delays the percolation of the pollutant to the piezometric surface. This class is located in isolated pockets in the western (medical plateau district), central (Lualaba district) and southern (commercial district) sectors of the municipality of Makiso.

3) High degree of vulnerability: occupying almost the entire study area, i.e. $96.5 \%$ of the surface of the municipality of Makiso. These areas correspond to flat surfaces where the topographic slope is very small. The high degree of vulnerability can be explained by the shallow depth of the water table (less than 1.5 $\mathrm{m}$ ) combined with the low slope of the land (less than $2.0 \%$ ). These conditions promote the infiltration of any contaminants present at the surface. It should also be noted that the increase in the degree of vulnerability in these sectors is linked to the nature of the soil (sandy texture or absent as a result of intense anthropic activities), the vadose zone corresponding to clayey sands and the aquifer, which is made up of sandy gravels (coarse materials and therefore permeable), which can facilitate the rapid circulation of water (pollutants).

Figure 5 shows the distribution of the surface area in $\%$ of the degree of vulnerability to pollution of the studied water table. It can be seen that the high degree of vulnerability occupies almost the entire study area, i.e. $96.5 \%$ of the surface area of the Makiso municipality.

\subsection{Validation of the Vulnerability Map}

Any vulnerability map developed should be tested and validated by measurements of physico-chemical and bacteriological parameters in order to assess the deterioration of groundwater quality. In the validation of vulnerability maps, the really contaminated areas should correspond to those with the highest vulnerability indices. A vulnerable area may also have a low vulnerability index because the notion of vulnerability is not synonymous with actual pollution, but rather with a predisposition of these areas to possible contamination if nothing is done to protect them. For our purposes, we will test the validity of vulnerability to nitrate pollution in groundwater by comparing the spatial distribution of nitrates in groundwater with the distribution of vulnerability classes.

The spatial distribution of nitrate is based on the Kriging interpolation of $\mathrm{NO}_{3}^{-}$data across the Makiso municipality. Nitrate concentrations in the analyzed groundwater vary between 0.01 and $0.13 \mathrm{mg} / \mathrm{l}$. These concentrations are below the drinking water threshold of $50 \mathrm{mg} / \mathrm{l}$, which means that the samples analyzed are not polluted by nitrates compared to the standards set by the World Health Organization (WHO). The map in Figure 6 shows the spatial distribution of nitrate concentrations. 


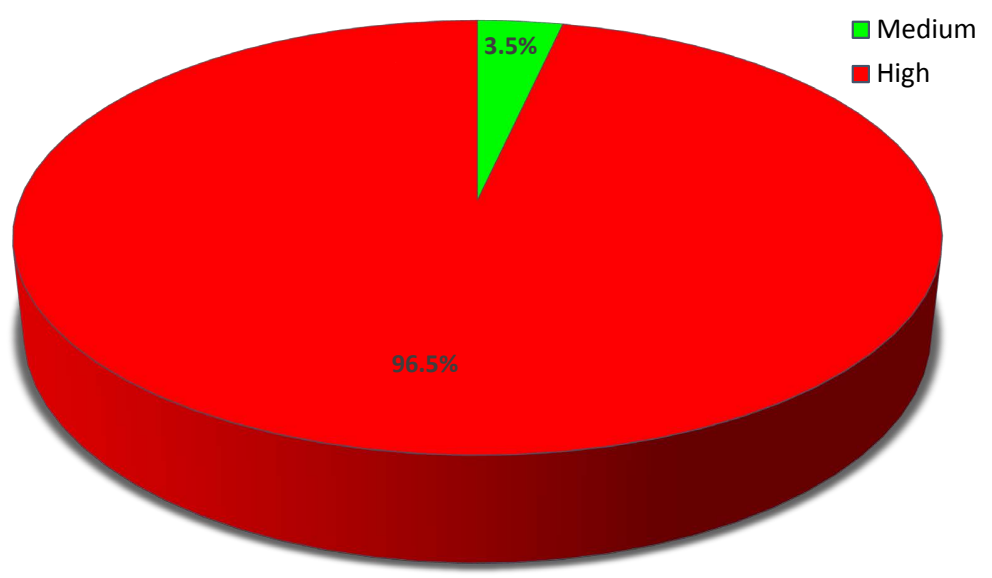

Figure 5. Distribution of groundwater pollution vulnerability levels in Makiso municipality.

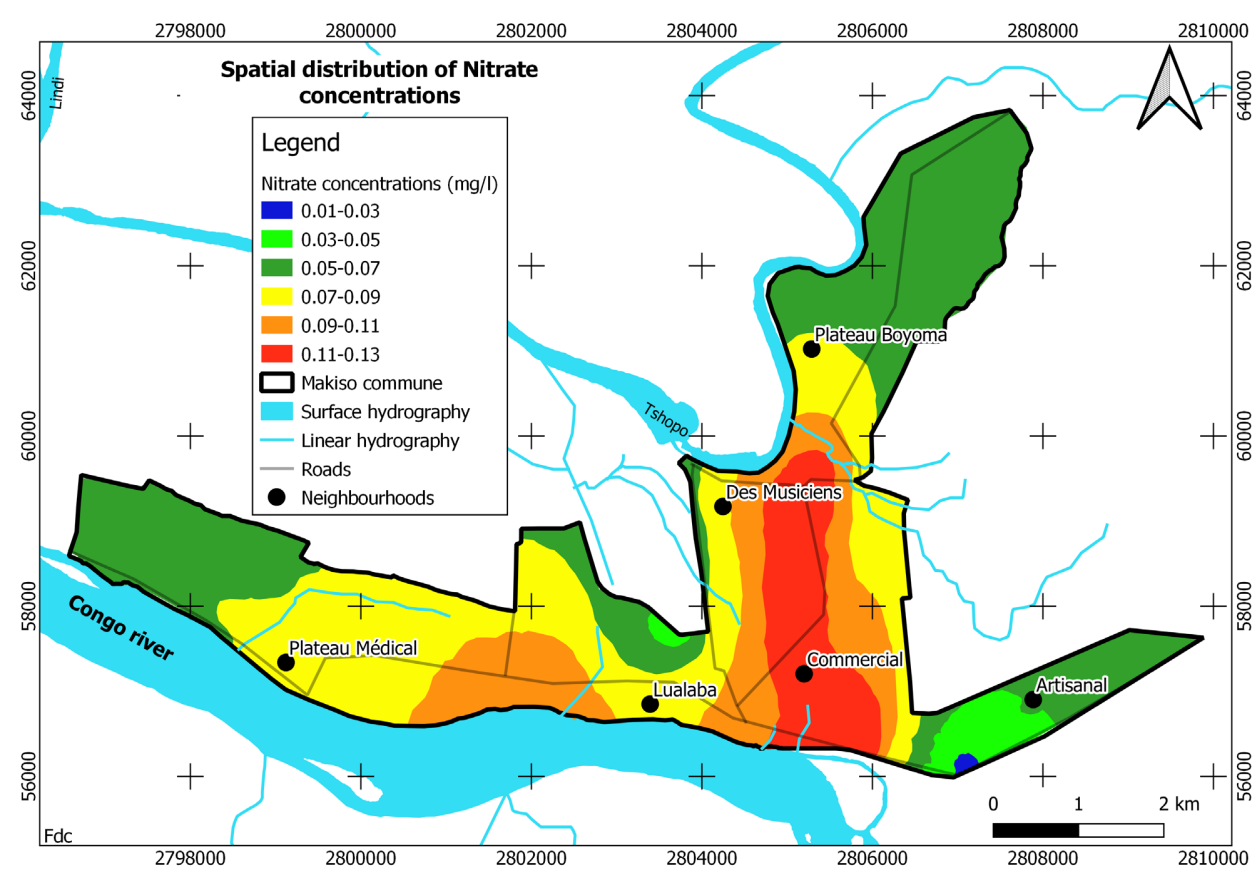

Figure 6. Spatial distribution of nitrate concentrations in groundwater in Makiso municipality

Comparing the Nitrate distribution map with the vulnerability map, we can see that it is more the central part (commercial district) where Nitrate levels increase from south to north. We can see that the area with a high degree of vulnerability correlates with nitrate concentrations above $0.11 \mathrm{mg} / \mathrm{l}$. On the other hand, there are other areas with low nitrate concentrations (below $0.05 \mathrm{mg} / \mathrm{l}$ ) such as in the south-east of the study area at the level of the Artisanal district, which corresponds to high vulnerability indices. This can be explained by the absence of surface sources of nitrate pollution in these areas.

\section{Conclusion}

The assessment of the vulnerability to groundwater pollution of the Makiso mu- 
nicipality in Kisangani, carried out by applying the DRASTIC method and the Geographic Information System (GIS), revealed a major trend in the vulnerability of the groundwater concerned. Two degrees of vulnerability were highlighted (medium and high), with variations in DRASTIC indices of [141 - 145] for the medium degree and [146 - 175] for the high degree. The most dominant degree is the high degree, which represents almost the entire municipality studied (96.5\%). This allows us to conclude that this groundwater is threatened locally by the infiltration of pollutants from the soil surface. The average degree representing $3.5 \%$ of the surface area of our study sector may change due to the combined effects of man and rainfall. The nitrate distribution map was used for the validation of the groundwater vulnerability model. The nitrate concentrations obtained for the water samples analyzed vary between 0.01 and $0.13 \mathrm{mg} / \mathrm{l}$. These concentrations are below the WHO potability threshold of $50 \mathrm{mg} / \mathrm{l}$. The comparison between the nitrate distribution map and the final vulnerability map shows that the areas defined as highly vulnerable by the DRASTIC method and the areas with high nitrate concentrations (above $0.11 \mathrm{mg} / \mathrm{l}$ ) are in agreement. On the other hand, there are other areas with low nitrate concentrations (below $0.05 \mathrm{mg} / \mathrm{l})$ which correspond to the high vulnerability indices. This can be explained by the absence of surface sources of nitrate pollution in these areas.

\section{Conflicts of Interest}

The authors declare no conflicts of interest regarding the publication of of this paper.

\section{References}

[1] Murhula, E., Kutangila, S., Birhenjira, E. and Muyisa, S. (2019) Hydrogéochimie et susceptibilité à la contamination des eaux souterraines dans le secteur de Panzi, ville de Bukavu, RD Congo. Geo-Eco-Trop, 43, 197-209.

[2] Sinan, M., Maslouhi, R. and Razack, M. (2003) Utilisation des SIG pour la caractérisation de la vulnérabilité et de la sensibilité à la pollution des nappes d'eau souterraine. Application à la nappe du Haouz de Marrakech, Maroc. 1-15. https://www.fig.net/resources/proceedings/fig_proceedings/morocco/proceedings/T S11/TS11_3_sinan_et_al.pdf

[3] Mbuluyo, M., Mashauri, F. and M'putu, P. (2017) Cartographie de la vulnérabilité à la pollution de la nappe souterraine d'Isiro (Nord-est de la RD Congo) à partir de la méthode DRASTIC. Afrique Science, 13, 125-139.

[4] Hamza, M.H., Added, A., Francés, A. and Rodriguez, R. (2007) Validité de l'application des méthodes de vulnérabilité DRASTIC, SINTACS et SI à l'étude de la pollution par les nitrates dans la nappe phréatique de Metline-Ras Jebel-Raf Raf (Nord-Est Tunisien). Comptes Rendus Geoscience, 339, 493-505. https://doi.org/10.1016/j.crte.2007.05.003

[5] Kazadi, Z.A. (2012) Contribution à l'étude de la qualité et de la gestion de l'eau de bosson dans la région de Kisangani. Thèse de doctorat inédit, Université de Kisangani, Kisangani, 217 p.

[6] Nyakabwa, M. (1982) Phytocénose de l'écosystème urbain de Kisangani. Thèse de doctorat inédit, Faculté des Sciences, Université de Kisangani, Kisangani, 15-72. 
[7] Upoki, A. (1990) Aperçu systématique et écologique des espèces aviennes de la reserve forestière de Masako et ses environs (Kisangani, Haut-Zaïre). Dissertation de DES., inédit, Faculté des Sciences, Université de Kisangani, Kisangani, 77 p.

[8] Verbeek, T. (1970) Géologie et lithologie du Lindien (Précambrien supérieur du Nord de la République Démocratique du Congo). Musée royal de l'Afrique central, Tervuren, Belgium, 309 p.

[9] Verbeek, T. and Ladmirant, H. (1972) Notice explicative de la carte du Lindien dans les régions de l'Aruwimi-Ituru et du Bas-Uele. Carte géoloique à l'échelle du 1/500.000. Republique du Zaïre, Dépt. des Mines, direction du Service géologique, Kinshasa, Lubumbashi, Bukavu, 55 p.

[10] Lepersonne, J. (1974) Carte géologique du Zaïre au 1/2000.000 et Notice explicative. République du Zaïre, Département des mines, Direction de la Géologie, Kinshasa.

[11] Lepersonne, J. (1977) Structure géologique du bassin intérieur du Zaire. Bulletins de P Académie Royale de Belgique, 63, 941-965.

https://doi.org/10.3406/barb.1977.58328

[12] Fernandez-Alonso, M., Kampata, D., Mupande, J.-F., Dewaeles, S., Laghmouch, M., Baudet, D., Lahogue, P., Badosa, T., Kalenga, H., Onya, F., Mawaya, P., Mwanza, B., Mashagiro, H., Kanda-Kula, V., Luamba, M., Mpoyi, J., Decree, S. and Lambert, A. (2015) Carte géologique de la République Démocratique du Congo au 1/2.500.000. Notice explicative, Ministère des mines, République Démocratique du Congo.

[13] Murat, V. (2000) Etude comparative des méthodes d'évaluation de la vulnérabilité intrinsèque des aquifères à la pollution: Application aux aquifères granulaires du piémont laurentien. Mémoire de maitrise en Sciences, Université du Québec, INRSGéoressources, 291 p. https://espace.inrs.ca/id/eprint/326/1/Tg00006.pdf

[14] Aller, L., Bennet, T., Lehr, J.H., Petty, R. and Hackett, G. (1987) DRASTIC: A Standardized System to Evaluate Ground Water Pollution Potential Using Hydrogeologic Settings. US-EPA Report 600/2-87-035, 622 p.

[15] Foster, S.S.D (1987) Fundamental Concepts in Aquifervulnerability, Pollution Risk and Protection Strategy. TNO Comm. Hydrol. Res. Proc. \& Information, 38, 69-86.

[16] Van Stempvoort, D., Ewert, L. and Wassernaa, R.L. (1992) AVI: A Method for Groundwater Protection Mapping in the Prairie Provinces of Canada. PPWD Groundwater and Contaminants Project. National HydrologyResearch Institute, Saskatoon.

[17] Dibi, B., Kouassi, K.I., Konan-Waidhet, A.B., Savance, I., Biemi, J., Nedeff, V. and Lazar, G. (2012) Impact of Agriculture on the Quality of Groundwater Resources in Peri-Urban Zone of Songon (Cote D’Ivoire). Environnement Engineering and Management Journal, 11, 2173-2182. https://doi.org/10.30638/eemj.2012.271

[18] Dibi, B., Kouassi, K.L., Kouame, K.I., Konan, K.S., Soumahoro, M., Onan-Waidhet, A.B. and Gnakri, D. (2013) Evaluation de la vulnérabilité à la pollution des aquifères des formations altérites à partir des méthodes DRASTIC et SYNTACS: Cas de la ville de M’bahiakro, Centre de la Côte D’Ivoire. International Journal of Innovation and Applied Studies, 2, 464-476.

[19] Jourda, J.P., Kouame, K.J., Adja, M.G., Deh, S.K., Tanani, A., Teffini, A. and Biemi, J. (2007) Evaluation du degré de protection des eaux souterraines: Vulnérabilité à la pollution de la nappe de Bonoua (Sud-Est de la Côte d'Ivoire) par la méthode DRASTIC. In: Conférence Francophone ESRI, Versailles, 10-11 Octobre 2007, 15 p. http://www.esrifrance.fr/sig2007/cocody_jourda.htm

[20] Lallemand, A. and Barres, A. (1994) Normalisation des critères d'établissement des cartes de vulnérabilité aux pollutions. Rapport BRGM/R37928, Orléans, France, 17 p. 